\title{
INTRAMEDULLARY SPINAL CORD METASTASES
}

\author{
A Clinico-pathological Report of Three Cases
}

\author{
By \\ D. H. Sherbourne, B.Sc., M.B., B.S. \\ C. R. TRIBE, M.A., D.M.(Oxon), D.T.M.\&H. \\ and \\ S. VARMA, B.Sc., M.B., B.S.
}

The Departments of Medicine and Morbid Anatomy and the National Spinal Injuries Centre,
Stoke Mandeville Hospital, Aylesbury, Bucks

Russell and Rubinstein (1959), when discussing spinal cord metastases, state that 'haematogenous intramedullary metastases are too rare for any generalisations'. Benson (1960) reviewed the literature and found only 24 reported cases. Of these the majority were associated with cerebral metastases. Chason et al. (1963) studied 200 patients with carcinoma metastatic to the central nervous system and found intramedullary spinal cord metastases in only Io patients (5 per cent.). Since this condition is both rare and difficult to diagnose in life, we present full clinico-pathological details of three further cases.

\section{CASE REPORTS}

Case I. The patient, a 69-year-old man, was admitted to Stoke Mandeville Hospital on I5th January 1962. He gave a previous history of cervical spondylosis first diagnosed in I952. He had suffered attacks of winter bronchitis since 1957, was dyspnoeic on exertion and had a chronic cough. Since 1959 he had been treated for arthritis with triamcinolone.

Two months before his present admission he fell and injured his back. Three days later he noticed pain in the left shoulder and gradually over the next few weeks the pain spread across to the neck and the right shoulder. Later he complained of pins and needles radiating down the right arm which he noticed had become weak and clumsy. Three days before admission he had difficulty in micturition, only voiding small amounts of urine. Two days before admission he developed pins and needles in the right leg, left hand and arm. He felt very weak and tired. His legs kept giving way under him when he walked. Increasing dyspnoea developed with cough productive of two eggcups full of greenish sputum daily and attacks of wheezing at night.

Clinical examination on admission showed a thin, frail wasted elderly man. There was tenderness over the sixth and seventh cervical spines with restriction of neck movements in all directions. The fingers were not clubbed but together with the knees showed severe osteoarthritis. He was barrel-chested and dyspnoeic on exertion. The cardiac and hepatic areas of dullness were diminished and there was slight impairment of the percussion note at the left apex. Poor vesicular breath sounds could be heard throughout the lungs. No abnormalities were noted in the cardiovascular system. The bladder was palpable half way up to the umbilicus, but rectal examination was normal.

His mental state, speech, cranial nerves and optic fundi were normal. There was patchy sensory loss to cotton wool and pin prick over the right leg and outer border of the right arm; absent vibration sense in the legs but proprioception was normal. Examination 
of the muscular system showed severe generalised muscle wasting and weakness, with occasional fasciculation of the biceps, triceps and quadriceps muscles more marked on the right side. In addition there was severe wasting of the interossei muscles of the right hand. The limb reflexes were all very brisk but the abdominal reflexes were absent. The left plantar response was flexor and the right extensor.

Investigations on admission showed the following results. Haemoglobin I03 per cent. (I $5 \circ$ g. \%), white cell count I5,000/c.mm., with a neutrophilia, ESR (Westergren) $24 \mathrm{~mm}$. in the first hour. Urine analysis negative for sugar and protein. Culture of

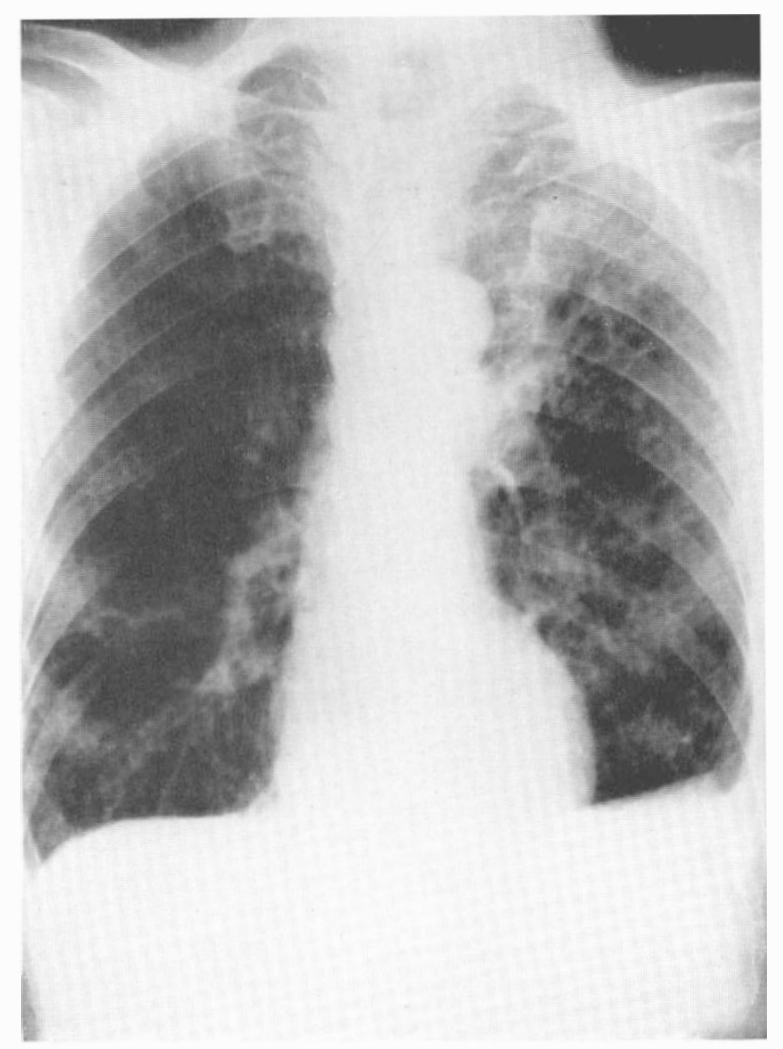

FIG. I

Case I. Chest radiograph during final illness.

sputum grew H. influenzae sensitive to tetracycline and Chloromycetin. Serum electrolytes were sodium I28, potassium 3.7 and chlorides IOI mEq./1. Blood urea $32 \mathrm{mg}$./ 100 ml., calcium $9.5 \mathrm{mg}$./ $100 \mathrm{ml}$., and phosphate $3.3 \mathrm{mg}$./100 ml. Wasserman and Kahn tests negative. Chest X-ray examination (fig. I) showed infiltration of the left upper zone with pleural thickening at the left base and generalised bronchitic changes. The radiologist's comment was that an active tubercular lesion could not be excluded. X-rays of the cervical spines showed severe osteoarthritis with disc degeneration between $\mathrm{C}_{3}$ and 4 and $\mathrm{C}_{5}$ and 6.

In view of the chest $\mathrm{X}$-ray findings specimens of sputum were examined for acid fast bacilli and malignant cells with no positive results. Lumbar puncture on I8th January I962 produced clear colourless CSF with an opening pressure of IoO $\mathrm{mm}$. water. On 
jugular compression the fluid rose freely but fell only slowly. The fluid contained three lymphocytes and eight red blood cells per c.mm. Protein was I IO mg./IOO ml. and the sugar $75 \mathrm{mg}$. $/ 100 \mathrm{ml}$. The Wasserman reaction was negative and the Lange 0000000000 .

He progressed rapidly downhill with increasing weakness of the limb, trunk and respiratory muscles together with complete retention of urine. He finally died from repiratory failure on 28th January 1962, I3 days after admission.

\section{Post-Mortem Findings}

The significant findings were confined to the respiratory system and the spinal cord. In the thoracic cage there was excess fluid at the right base and old adhesions at the right apex. The left pleural cavity was completely obliterated by old and recent adhesions, the anterior part of the left upper lobe being firmly adherent to the under surface of the sternum. The trachea and main bronchi contained thick green mucopus and there was evidence of recent tracheitis. The bifurcation lymph nodes were enlarged and congested but showed no evidence of tumour. A careful dissection of the bronchial tree showed no definite evidence of primary bronchial carcinoma. In the anterior part of the left upper lobe there was fairly extensive fibrous consolidation with small abscesses, areas resembling caseation and some calcification. On naked-eye examination this was thought to be an area of active fibro-caseous tuberculosis. However, on microscopy this region was extensively infiltrated by a poorly differentiated mucus-secreting adenocarcinoma. There were fairly extensive areas of tumour necrosis and the involved lung tissue was the site of severe old fibrosis. In places tumour masses could be seen within the lumen of medium sized pulmonary vessels. There was no histological evidence of tuberculosis and in the absence of any other primary adenocarcinoma in the body this picture was considered to be a primary adenocarcinoma arising in an area of scarred lung tissue. This association has been frequently reported, Carroll (1962). The remainder of the left and the right lung showed gross widespread emphysema with evidence of severe recent bronchitis in the lower lobes.

All the bones of the vertebral column were unusually soft suggesting generalised osteoporosis. On removing the spinal cord there was no naked-eye evidence of narrowing of the spinal canal in the cervical region. The spinal cord was removed intact from $\mathrm{C}_{2}$ to LI. On opening the dura the cervical cord appeared swollen and softened especially between $\mathrm{C}_{3}$ and $\mathrm{C}_{7}$. Sections taken from the spinal cord showed a large intramedullary metastatic tumour on the left side of the cord at the level of the origin of the sixth cervical nerves. It had caused gross distortion of the remaining cord tissue and its histological structure was similar to the adenocarcinoma found in the lung (fig. 2). A small amount of this tumour had extended downwards into the seventh cervical segment. Sections taken from the fifth cervical segment showed no evidence of tumour but there was marked vascular endothelial proliferation on the right side. Sections from $\mathrm{C}_{3}$ and $\mathrm{C}_{2}$ showed congestion and swelling of the posterior columns which were infiltrated by numerous fat laden macrophages. Sections from the thoracic cord showed no abnormalities and there was no evidence of demyelination (Loyez stain).

The brain was carefully sliced at approximately $\mathrm{I} \mathrm{cm}$. intervals and showed anoxic mottling of the basal ganglia but no naked-eye evidence of metastases. Sections from the cerebrum, thalami, cerebellum, pons and medulla showed no abnormalities. Histological examination of muscle taken from the left thenar eminence showed no evidence of the changes reported in Triamcinolone myopathy (Williams, I959) or any other abnormalities. There were no significant changes in the remaining organs and no evidence of tumour metastases elsewhere in the body.

\section{Comment on Case I}

During life this patient was suspected of suffering from a carcinomatous neuromyopathy because of his atypical chest X-ray, hyponatraemia (Williams, 
I963) and rapidly progressive muscular weakness. Efforts to make a firm diagnosis were complicated by evidence of cervical spondylosis and a history of prolonged triamcinolone therapy-a steroid known to cause myopathy (Hume Kendall \& Hart, I959; Williams, I959). The diagnosis was still not apparent at the end of the post-mortem examination. Histology revealed a large solitary intramedullary metastasis in the sixth cervical segment of the spinal cord arising from an adenocarcinoma which had developed in scarred lung tissue at the apex of the left upper lobe. No metastases were found in the brain or elsewhere in the body.

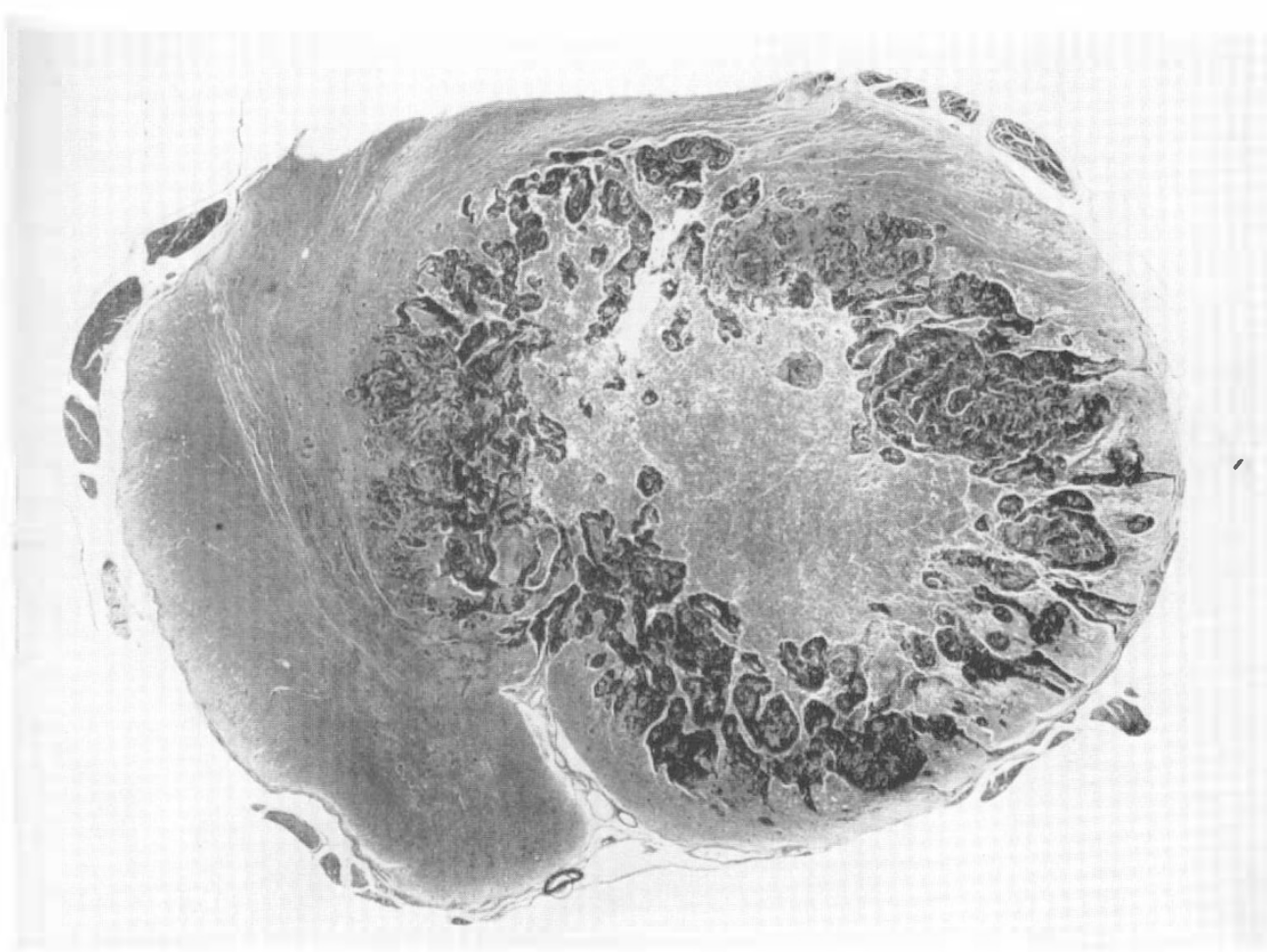

FIG. 2

Case I. Low power view of section taken from the sixth cervical segment of the spinal cord.

$(\mathrm{H}$ and $\mathrm{E} \times 8$.)

Case 2. The patient, a 60-year-old man, was admitted to the National Spinal Injuries Centre, Stoke Mandeville Hospital, on 22nd February 1963. He gave a previous history of having felt a sharp pain in the mid-scapular region while driving his car six weeks prior to admission. Following this he noticed slight dragging of his right leg. Some days later the left leg was similarly affected and on 2 Ist January I963 he was admitted to the Friarage Hospital, Northallerton, with retention of urine. At this time he was found to have incomplete loss of all forms of sensation from below the eighth thoracic segment. There was marked spastic weakness of the legs with extensor plantar responses. Lumbar puncture showed no evidence of blockage of the spinal canal. The $\mathrm{CSF}$ was clear and contained $30 \mathrm{mg}$./ $100 \mathrm{ml}$. protein and less than one white cell per c.mm. The CSF Wasserman reaction and Lange curve were negative. A chest X-ray at this 
time showed no abnormality. X-rays of the spine showed some osteoarthritic lipping with loss of joint spaces in the thoraco-lumbar region but no abnormalities at higher levels. A myelogram showed no evidence of spinal cord compression. A provisional diagnosis of transverse myelitis was made and he was treated with large doses of prednisone $(30 \mathrm{mg}$. three times a day tapering down to $2.5 \mathrm{mg}$. twice a day) which produced no signs of clinical improvement.

He was transferred to this hospital for rehabilitation, and on admission (22nd February 1963) he was found to have an incomplete transverse spinal cord syndrome below the third thoracic segment and there was a bilateral horizontal nystagmus. There were superficial pressure sores over both buttocks and a urinary infection due to Bact. coli. Since he complained of persistent abdominal discomfort with anorexia a fasting test meal was performed which showed absence of free hydrochloric acid. A barium meal showed a slight reflux into the oesophagus but no evidence of gastric or duodenal ulceration and no signs of neoplasms.

By the middle of March his general condition had deteriorated and he was complaining of dizziness and headache. From this time he became increasingly confused and disorientated in time and space. Near the end of March he was found to have a labile blood pressure which varied from $80 / 50$ to $180 / 90$ and the fundi showed signs of very early papilloedema. He also developed a mild right facial paresis and his spinal cord lesion was now complete below T3. A malignant lesion which had first developed in the spinal cord and was now involving the brain was suspected and further investigations were undertaken. A lumbar puncture on 26th March 1963 showed a raised pressure of $220 \mathrm{~mm}$. water with eight lymphocytes per c.mm. and I30 mg./100 ml. of protein in the cerebrospinal fluid. The ESR (Westergren) was slightly raised to $19 \mathrm{~mm}$. in the first hour, but his blood counts, blood urea, liver function tests and serum electrolytes were all within normal limits. X-rays of the skull were also normal. During this period he had a persistent cough producing a moderate amount of sputum which did not respond to antibiotics, bronchodilators and physiotherapy. An X-ray of his chest on 29th March I963 (fig. 3) showed bronchitic changes with some basal emphysema. On 4th April 1963 he started to have epileptiform attacks with unconsciousness. Late the next day he lapsed into a deep coma and died.

\section{Post-Mortem Findings}

The body was that of a well-nourished middle-aged man. Internally there were no pleural adhesions and no excess fluid in the pleural cavities. The trachea and main bronchi were filled with creamy pus. The lungs were acutely congested and oedematous and showed generalised fairly severe emphysema with evidence of acute bronchitis and early peri-bronchial bronchopneumonia. In the centre of the right lower lobe, surrounding the first major posterior branch of the right lower lobe bronchus, there was a firm white tumour $\frac{3}{4}$ " in diameter infiltrating into the adjacent lung tissue. Histology showed this to be an anaplastic squamous cell carcinoma of the 'oat-cell' variety arising from the wall of a major bronchus. The hilar and bifurcation lymph nodes were not involved by tumour. The heart showed no significant abnormalities.

In the abdomen the intestinal tract appeared normal but the liver was acutely congested and on section showed multiple small metastases up to $\frac{1}{2}$ in diameter. Both adrenal glands were grossly enlarged due to tumour deposits- $I$ " in diameter on the left side and $21^{\prime \prime} \times \mathrm{I}^{\prime \prime} \times \mathrm{I}^{\prime \prime}$ on the right side. The hepatic and adrenal metastases showed a similar histological picture to that seen in the primary lung tumour. The kidneys were normal but the bladder showed a mild chronic cystitis.

The only abnormality on carefully slicing the brain was one metastasis $\frac{1}{2}$ " in diameter surrounded by some cerebral softening situated in the cerebral cortex of the under surface of the left frontal lobe. The spinal canal showed no abnormalities after removal of the spinal cord. Naked-eye examination of the cord showed a segment of slight swelling in 
the region of the third thoracic segment and minute tumour-like nodules in the pia mater scattered over most of the posterior surface of the upper thoracic cord. Sections were examined from all segments of the spinal cord. These showed the presence of an intramedullary metastasis involving the second and third thoracic segments. At $\mathrm{T}_{2}$ the

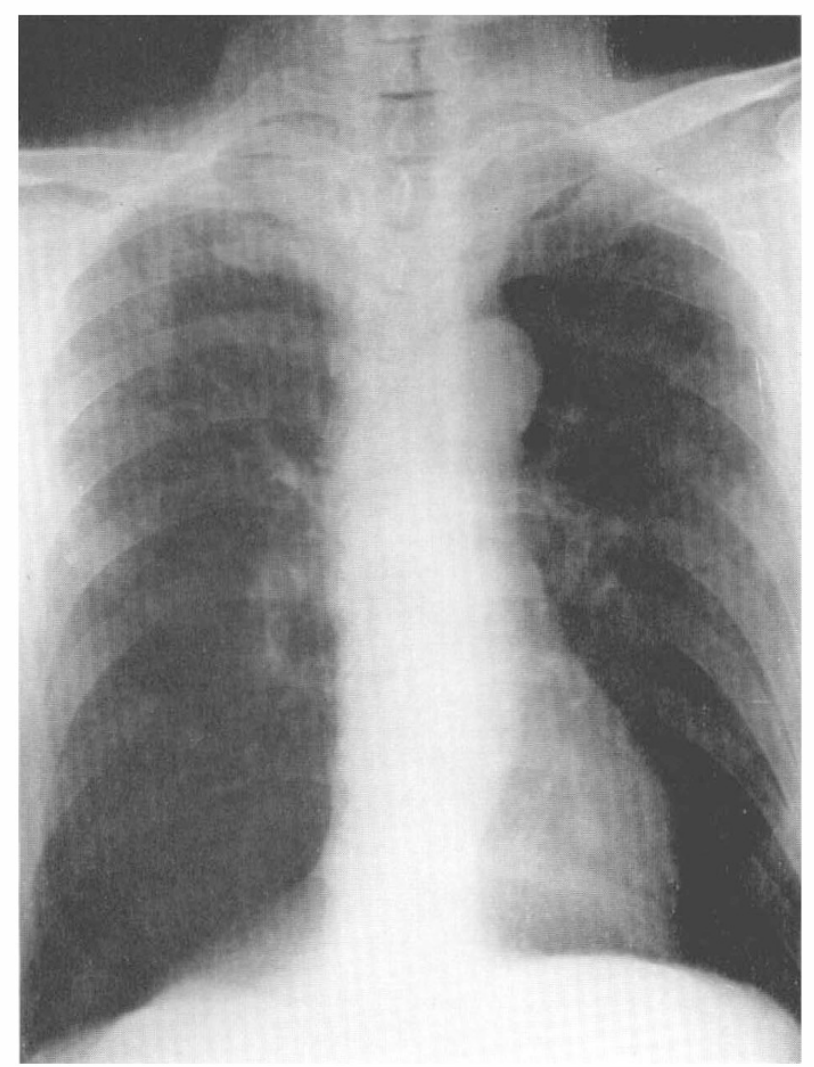

FIG. 3

Case 2. Chest radiograph during final illness.

metastasis replaced the central half of the cord (fig. 4). At $\mathrm{T}_{3}$ there was virtual replacement of the entire cord. The histological structure of this metastasis was similar to that of the primary tumour in the lung. At $\mathrm{C}_{7}, \mathrm{~T}_{2}, \mathrm{~T}_{3}$ and $\mathrm{T}_{5}$ there was evidence of early meningeal involvement by small groups of tumour cells. Although some of the capillaries in the spinal tissue surrounding the metastasis were thrombosed there was no evidence of recent or old thrombosis of the major spinal vessels. At $\mathrm{T}_{4}$ there was a 'core' of necrotic tissue and macrophages situated in the left lateral column close to the grey matter. This type of cylindrical cavity is frequently seen above and below traumatic lesions of the spinal cord (Holmes, I9I5). Sections from the remaining cervical and thoracic segments showed the characteristic pattern of ascending and descending degeneration.

\section{Comment on Case 2}

This patient presented as a nearly complete paraplegia in the upper thoracic region of fairly rapid onset. Thought originally to be due to transverse myelitis 
the rapid downhill progress with terminal signs of a cerebral space occupying lesion made a diagnosis of malignancy more likely. However, no primary growth was detected in life. The spinal cord lesion was thought to be due to a slowly progressive vascular lesion. At post-mortem examination a small oat-cell carcinoma in the right lung was found with haematogenous metastases in the liver, adrenals, cerebrum, spinal meninges and within the thoracic spinal cord.

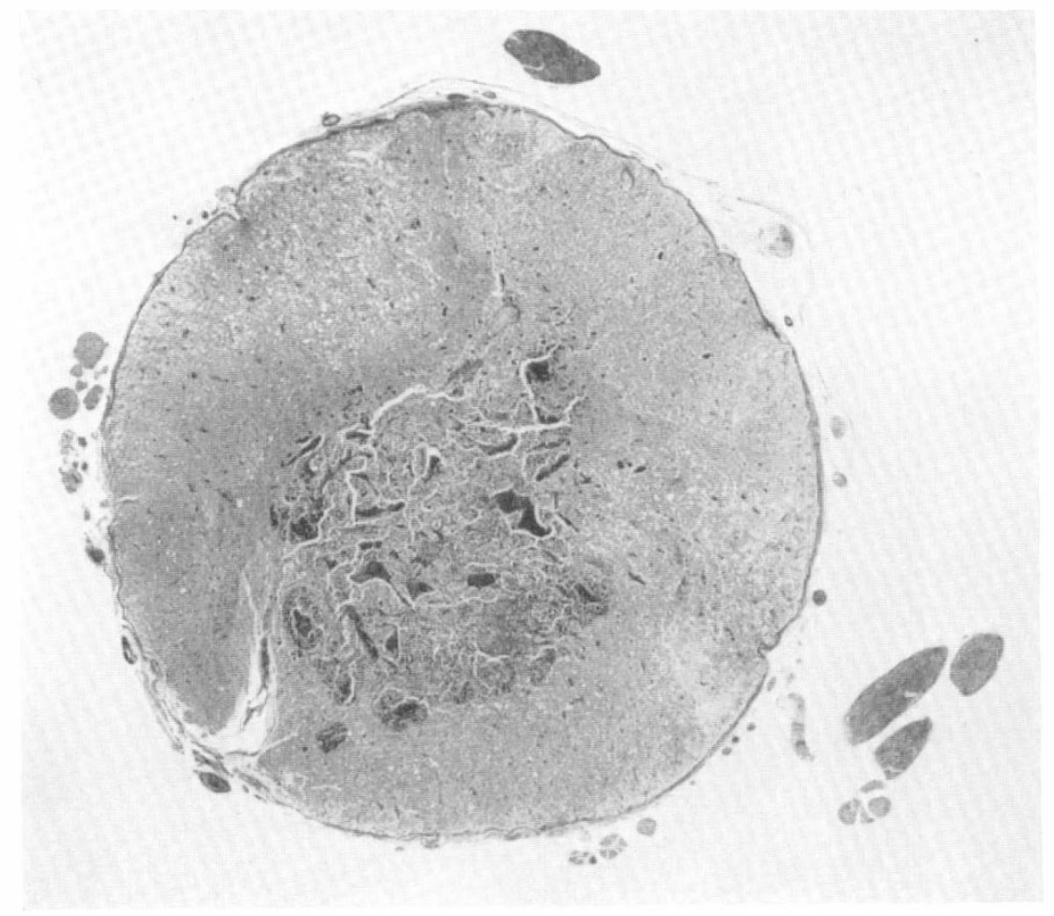

FIG. 4

Case 2. Low power view of section taken from the second thoracic segment of the spinal cord. ( $\mathrm{H}$ and $\mathrm{E} \times 8$.)

Case 3. The patient, a 53-year-old woman, was admitted to Stoke Mandeville Hospital on 5th June 1962. She had been quite well until the middle of April when she developed fever and a productive cough with generalised aching in her muscles. These symptoms improved, but two weeks later her right leg became weak and continued to become weaker over the next five days. Her left leg then also became weak and both legs became numb. Two days later she had difficulty in passing urine and was admitted to the Churchill Hospital, Oxford, on Ioth May 1962. On examination at this time she had a flaccid paraparesis with a sensory level between T6 and TIo. An initial diagnosis of virus myelitis was changed to carcinomatous myelopathy or secondaries in the dorsal spine when a chest X-ray was reported as follows. 'There is collapse of the left lung with gross elevation of the left diaphragm, presumably paralysed. More penetrated films show rounded lesions in the left lung and suggest left hilar enlargement' (fig. 5). Bronchoscopy was negative and no malignant cells were found in her sputum. X-rays of the spine showed only osteoarthritic changes. A myelogram was normal. 
She was transferred to Stoke Mandeville Hospital on 5th June 1962 for further investigation and physiotherapy. On admission there was clinical evidence of collapse and effusion at the left base. Examination of the nervous system showed a spastic paraparesis and hypoaesthesia to the level of $\mathrm{T}_{4}$. Investigations showed a haemoglobin of 78 per cent. (I I.4 g. \%), white cell count 6500 per $\mathrm{cmm}$. and an ESR (Westergren) of $5 \mathrm{I} \mathrm{mm}$. in the first hour. The serum alkaline phosphatase was $14.5 \mathrm{KA}$ units. Sputum culture at this time only grew normal commensals. In spite of thoracic paracentesis her lung condition progressed rapidly and she died on 25 th June 1962.

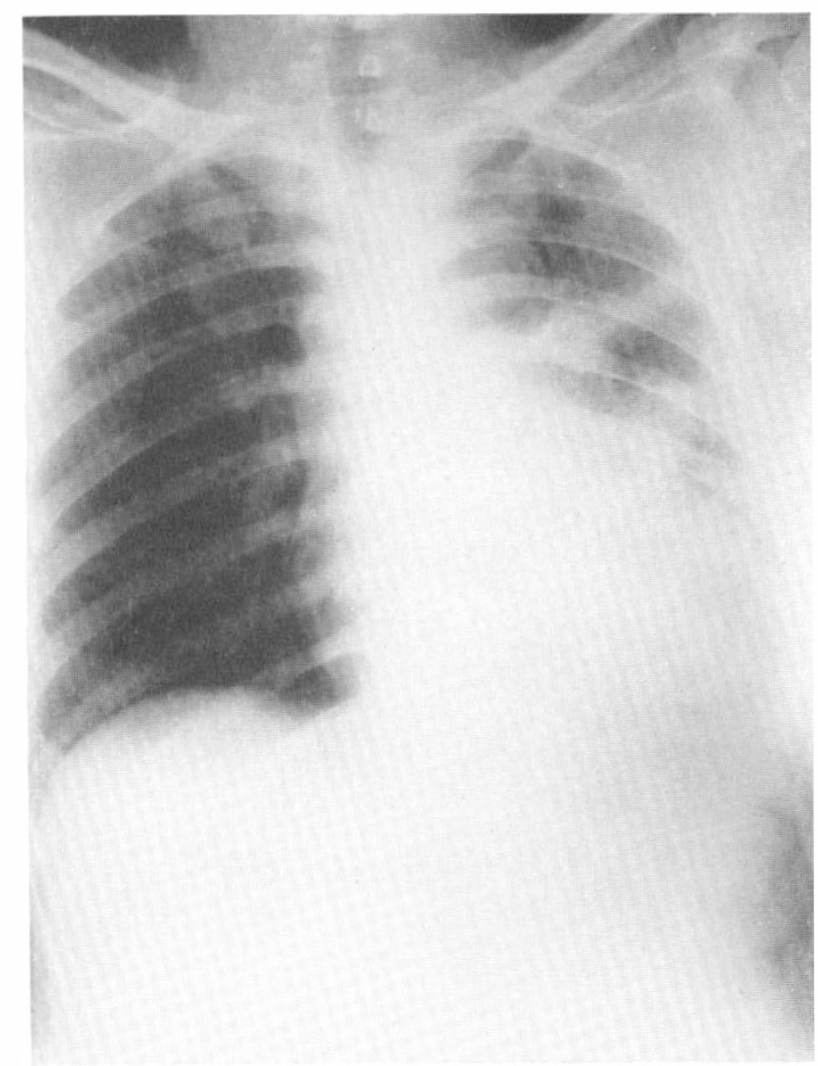

FIG. 5

Case 3. Chest radiograph six weeks prior to death.

\section{Post-Mortem Findings}

The significant findings were confined to the thorax and the central nervous system. The left pleural cavity was partially obliterated by adhesions and contained a little excess blood-stained fluid. The trachea and main bronchi contained a moderate amount of mucopus. Arising from the posterior branch of the left lower lobe bronchus there was a large circumscribed tumour approximately $3^{\prime \prime}$ in diameter which was extending into the surrounding lung tissue. The left hilar and paratracheal lymph nodes were enlarged due to secondary tumour deposits. There was also a metastatic growth $\frac{3}{4}$ " in diameter in the centre of the right upper lobe. Histological examination of all these tumours showed the 
typical appearance of an 'oat-cell' anaplastic squamous cell carcinoma of the lung. The remaining lung tissue on both sides showed evidence of widespread bronchitis but no true bronchopneumonia. The heart showed no gross abnormalities. No metastases were found in the abdominal cavity and the abdominal organs appeared normal apart from a severe calculous cystitis.

There was no evidence of metastases in the vertebral bodies. There was a large tumour plaque $\frac{3}{4}$ " in diameter adherent to the dura mater on the left side of the posterior fossa. On removing the brain this plaque was seen to be a direct extension from a large metastasis in the left cerebellar hemisphere. The brain was oedematous and swollen and on slicing there were numerous small and medium sized metastases in the periphery of the cerebral cortex in both frontal lobes and the left occipital lobe. In addition there was a larger metastasis $\frac{3}{4}$ " in diameter involving the left caudate nucleus and basal ganglia which appeared to have caused extensive recent infarction of the adjacent white matter. Both cerebellar hemispheres contained large metastases. The spinal cord was removed intact and external examination showed swelling and softening of the cord from the fourth cervical to the second thoracic segments. The spinal meninges showed no evidence of tumour involvement. Histological examination of the spinal cord revealed a large intramedullary metastasis extending from the third to the sixth thoracic segments. In the fourth (fig. 6) and fifth segments the tumour had virtually replaced the entire cord tissue.

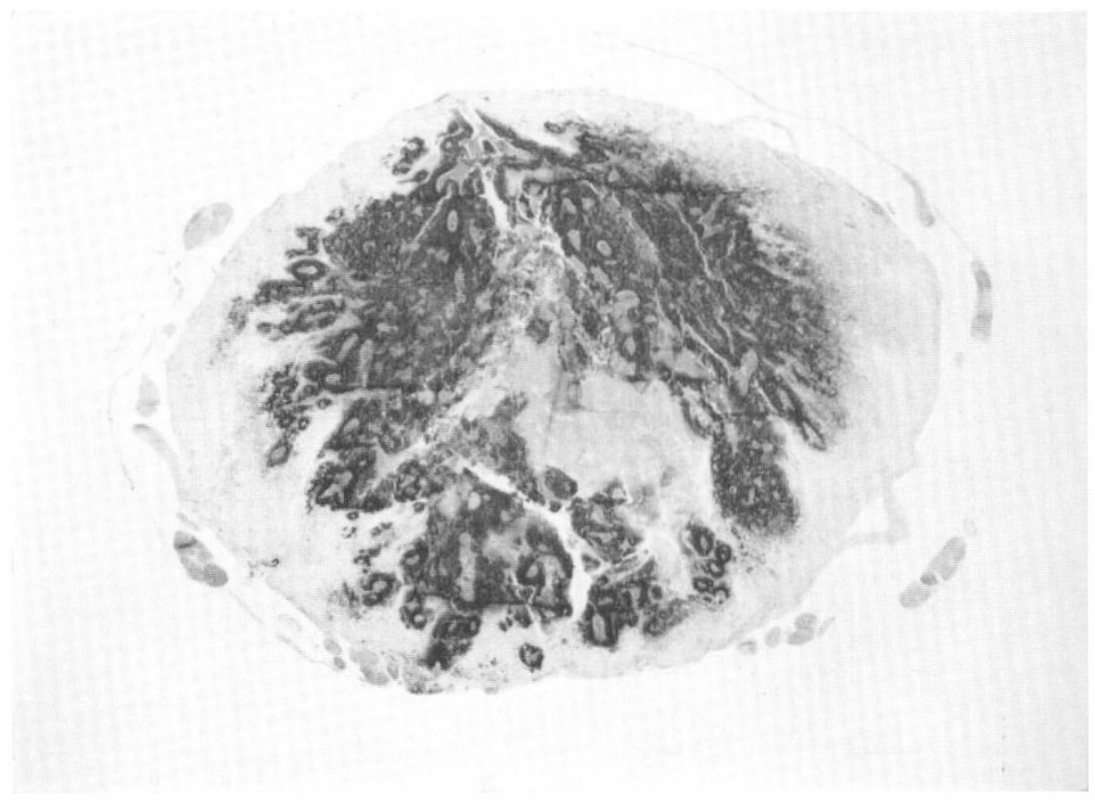

FIG. 6

Case 3. Low power view of section from the fourth thoracic segment of the spinal cord. ( $\mathrm{H}$ and $\mathrm{E} \times 8$.)

On microscopy this tumour and the cerebral metastases all showed an oat-cell carcinomatous pattern similar to that seen in the primary lung tumour. Sections from TI and T2 showed marked endothelial hyperplasia of vessels within and around the central canal and there appeared to be acute necrosis and recent infarctive changes in this region extending up as high as the fourth cervical segment. 


\section{Comment on Case 3}

This patient presented with a mid-thoracic paraparesis thought originally to be due to virus myelitis. However, an abnormal chest $\mathrm{X}$-ray made a diagnosis of carcinomatous myelopathy more likely. No histological or cytological evidence of malignancy was established during life. At post-mortem examination a large 'oatcell' carcinoma of the left lung with intrathoracic spread was found. There were associated multiple cerebral metastases and a large intramedullary spinal cord metastasis involving the third to the sixth thoracic segments.

\section{DISCUSSION}

In a recent article Lord Brain (1963) divided the neurological complications of neoplasms into metastatic and non-metastatic. He noted that haematogenous metastases of the spinal cord are very rare. The non-metastatic complications are of special interest at the present time and recently Croft and Wilkinson (1963) found neurological abnormalities indicative of neuromyopathy in 40 out of 250 men with carcinoma of the lung ( 16 per cent.). Awareness of a condition is the first step to its diagnosis and with the current interest in carcinomatous neuromyopathy it is not surprising that this diagnosis was made in two out of the three cases of intramedullary spinal cord metastases reported in this paper. Even when cerebral metastases were suspected in the terminal stages of Cases 2 and 3 their original paraplegic conditions were thought to be due to vascular lesions or compression from secondary deposits in the spine. The fact that there was histological evidence of infarction adjacent to the spinal metastases in all three cases suggests that the first signs of paraplegia in these and other similar cases may be due to vascular involvement.

Is there any evidence to suggest that intramedullary metastases are more common than reported? In 1952 Willis was able to quote I 2 cases of blood-borne metastatic growths in the spinal cord from the literature. Only four of these cases had spinal cord involvement without simultaneous cerebral metastases. Commenting on this apparent rarity he stated 'metastatic growths in the spinal cord may be less rare than is supposed. This organ is seldon examined in routine necropsy work unless there have been clinical symptoms of disease in it, and symptoms due to cord lesions may often be submerged by those due to co-existing cerebral lesions'. Benson (1960) reviewed the literature and could find only 24 reported cases of intramedullary spinal cord metastases. Chason et al. (1963) published a prospective autopsy study on metastatic carcinoma in the central nervous system. They found carcinoma metastatic to the central nervous system in 200 (I8.3 per cent.) of I096 patients with carcinoma. The spinal cords were examined in all cases and intramedullary metastases were found in ro patients ( 5 per cent.); or approximately I per cent. in all cases of malignant disease. Six of these arose from bronchogenic carcinoma, but they do not report either the histological nature of the primary tumours or whether any of the metastases were solitary. At this time these authors had found 27 previously reported cases in the literature. If their Io additional cases are combined with the three reported in this paper the total of reported cases to date must be around 40.

When one remembers that, in comparison with the brain where there are many 'silent' areas, space occupying lesions of the spinal cord rapidly give rise to clinical 
signs and symptoms; there is an obvious discrepancy here between the small number of reported cases and the incidence of I per cent. of intramedullary spinal cord metastases in all cases of malignant disease reported by Chason et al. (I963). Since there is no reason to dispute the meticulous work of these workers, another explanation must be sought. It seems likely that for reasons probably related to blood supply spinal cord metastases rarely occur before cerebral metastases and when they do occur the signs and symptoms are misinterpreted, or not even sought for, in the terminal phases of the disease. Only when the metastases are solitary (as in Case I) or occur before cerebral metastases (as in Cases 2 and 3 ) is the diagnosis likely to be confirmed at necropsy and the cases reported.

All authors are agreed that carcinoma of the lung is the commonest source of secondary neoplasms of the brain. The histological type most likely to metastasise is still the subject of debate. Whereas it seems generally agreed that the squamous type is less prone to metastasise than other varieties, 'oat-cell' carcinoma predominated in Meyer and Reah's series (1953) and adenocarcinoma was prevalent in the series of Galluzzi and Payne (1956). Remembering the few reported cases, haematogenous metastases in the spinal cord appear to follow the general pattern of metastases elsewhere in the central nervous system. Ten out of the 24 cases reviewed by Benson (1960), six out of the Io cases reported by Chason et al. (I963) and all the three cases reported in this paper originated from the lung. It seems likely that the histological type of haematogenous metastases in the spinal cord derived from lung carcinomata will resemble those found in the brain when significant numbers have been reported.

\section{SUMMARY}

Full clinical and pathological details are presented of three cases of intramedullary spinal cord metastases. One of these was solitary in nature, the remaining two were associated with cerebral metastases. All three cases derived from carcinomata of the lung.

The diagnosis in all three cases was only revealed at necropsy and the reasons for this are discussed. The incidence of this disease is thought to be higher than the few number of previously reported cases indicates.

\section{ACKNOWLEDGMENTS}

We wish to thank Dr. V. E. Lloyd Hart for permission to publish Case I; Dr. L. Guttmann, Case 2; and Dr. C. W. M. Whitty, Case 3. We also wish to thank Dr. H. J. Harris for permission to quote from his post-mortem report on Case 2 and Mr. D. G. Standen for the excellent photographs.

\section{RÉSUMÉ}

Les détails cliniques et pathologiques de trois cas de métastases intramédulaires sont présentés. Dans un des cas la métastase était solitaire, dans les deux autres cas des métastases cérébrales furent trouvées. Dans les trois cas la tumeur d'origine était un carcinome du poumon. Le diagnostique, dans les trois, cas fut une découverte d'autopsie et la raison en est discutée. L'incidence de cette maladie est probablement plu sélevée que dans les quelques cas qui ont décrits dans la littérature médicale. 


\section{ZUSAMMENFASSUNG}

Volle klinische und pathologische Einzelheiten bei 3 Fällen von intramedullären Rückenmarksmetastasen werden beschrieben. In einem Fälle handelte es sich um eine solitäre Metastase, während in den beiden übrigen Fällen die Rückenmarksmetastase mit cerebralen Metastasen associiert war. In allen 3 Fällen waren Lungenkarzinome die Ursache.

In den 3 Fällen wurde die Diagnose erst durch die Autopsie erhoben und die Gründe hierfür werden diskutiert. Es wird angenommen, dass das Auftreten dieser Erkrankung häufiger ist als aus der geringen Zahl der früher berichteten Fälle zu schliessen ist.

\section{REFERENCES}

Benson, D. F. (1960). Neurology, 10, 28 I.

BRAIN, LORD W. R. (1963). Lancet, I, I79.

Carroll, R. (I962). F. Path. Bact. 83, 293.

Chason, J. L., Walker, F. B. \& LANDERS, J. W. (1963). Cancer, 16, 78I.

Croft, P. B. \& Wilkinson, M. (1963). Lancet, I, I84.

Galluzzi, S. \& Payne, P. M. (1956). Brit. F. Cancer, 10, 408.

Holmes, G. (1915). Brit. med. F. 2, 769.

Hume Kendall, P. \& Hart, M. F. (1959). Brit. Med. F. I, 682.

Meyer, P. C. \& ReAH, T. G. (1953). Brit. F. Cancer, 7, 438.

Russell, D. S. \& Rubinstein, L. J. (1959). Pathology of Tumours of the Nervous System, p. 222. London: Arnold.

Williams, R. S. (I959). Lancet, I, 769.

Williams, R. T. (1963). Brit. med. f. I, 233.

WILlis, R. A. (I952). The Spread of Tumours in the Human Body. 2nd Ed. p. 292. London: Butterworth. 